\title{
Controversy over Doctors of BC vote
}

A physician who is suing the British Columbia government over extra billing and patient access to private health care will lead the province's doctors in 2016.

Dr. Brian Day, co-owner of the forprofit Cambie Surgery Centre in Vancouver and former president of the Canadian Medical Association, was voted president-elect of Doctors of BC on May 26. Day beat opponent Dr. Alan Ruddiman, a rural physician and supporter of public provision of health care, by a single vote.

Day's victory stirred debate across social media about physician engagement in the provincial association and dissatisfaction with BC's public health system. Now, Doctors of BC will recount the vote. - Lauren Vogel, CMAJ

Read on at Storify.com

CMAJ 2015. DOI:10.1503/cmaj.109-5080

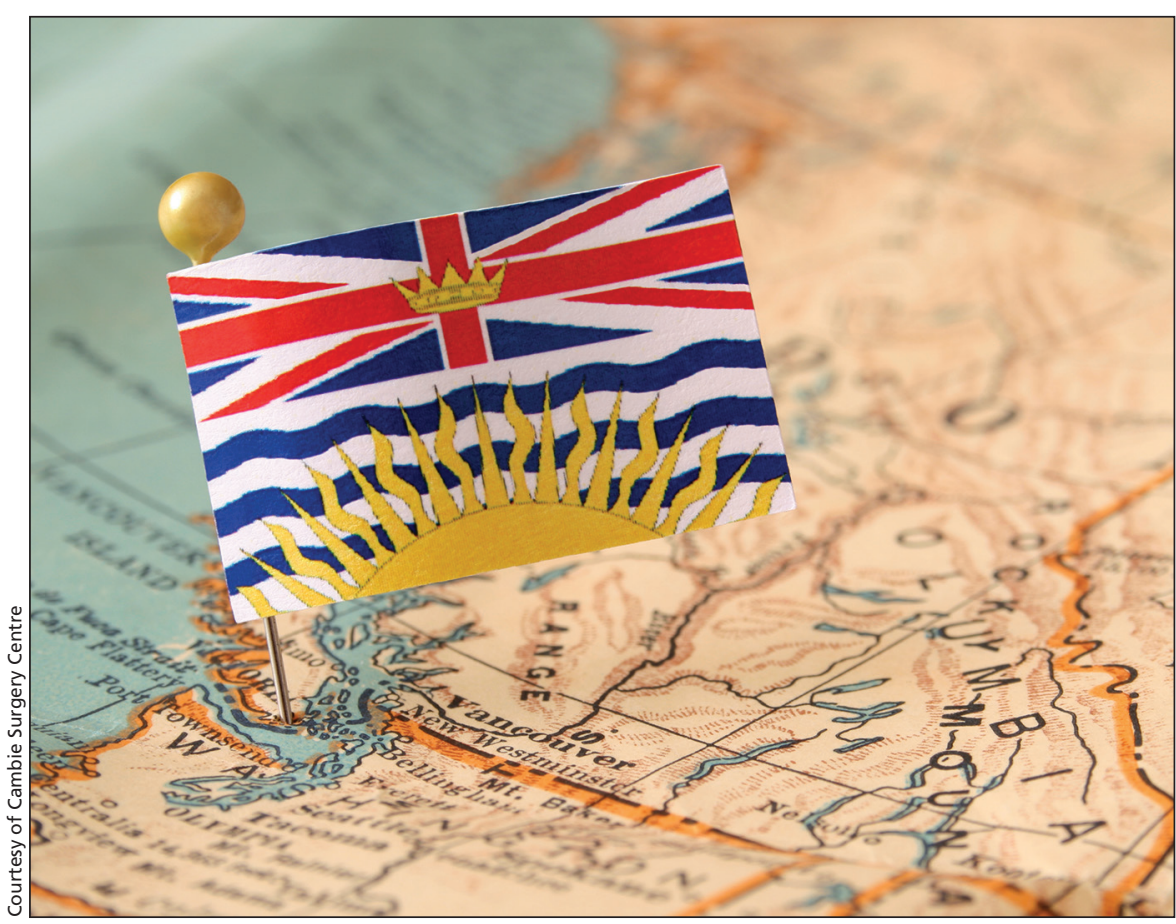

Private clinic owner Dr. Brian Day will lead Doctors of BC in 2016, pending a recount. 